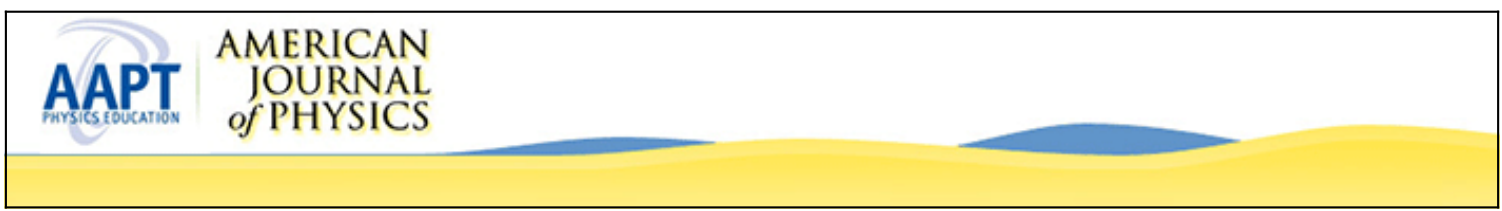

\title{
Light-operated millisecond timers
}

P. H. Gregson and W. P. Lonc

Citation: American Journal of Physics 44, 803 (1976); doi: 10.1119/1.10302

View online: http://dx.doi.org/10.1119/1.10302

View Table of Contents: http://scitation.aip.org/content/aapt/journal/ajp/44/8?ver=pdfcov

Published by the American Association of Physics Teachers

\section{Articles you may be interested in}

Light-operated accelerometer-type techniques

J. Acoust. Soc. Am. 93, 3536 (1993); 10.1121/1.405367

Light-operated solid-state switch for pulsed microwave power generator

Rev. Sci. Instrum. 51, 1571 (1980); 10.1063/1.1136101

Light-activated timer made from a pocket calculator

Phys. Teach. 16, 323 (1978); 10.1119/1.2339961

Radiation Exposure Timer for 12-Volt Operation

Rev. Sci. Instrum. 30, 1049 (1959); 10.1063/1.1716416

A Millisecond Timer

Rev. Sci. Instrum. 22, 359 (1951); 10.1063/1.1745938

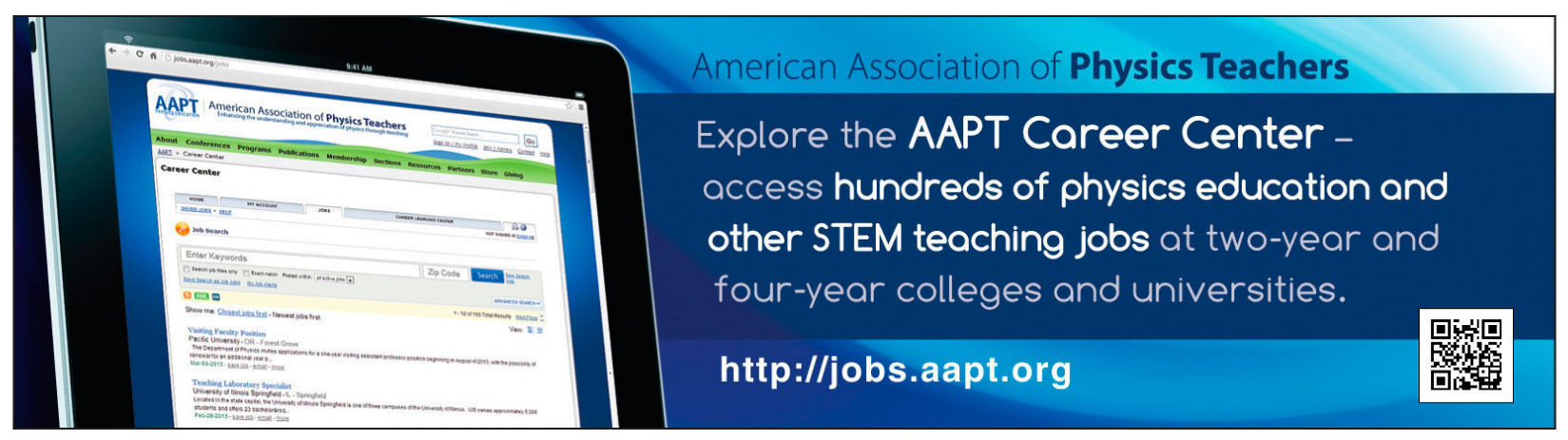




\title{
APPARATUS NOTES
}

Bruce G. Eaton, Editor

School of Physics and Astronomy, University of Minnesota, Minneapolis, Minnesota 55455

This department in collaboration with the Committee on Apparatus of the AAPT will welcome the submission of brief communications reporting new equipment, techniques, or materials of interest to teachers of physics. Notes on new applications of older apparatus, measurements supplementing data supplied by manufacturers, information which, while not new, is not generally known, procurement information, and news about apparatus under development are suitable for publication in this section. Neither the American Journal of Physics nor the Editors assume responsibility for the correctness of the information presented. Submit materials to: Bruce G. Eaton, Department of Physics, University of Minnesota, Minneapolis, Minnesota 55455.

\section{Light-operated millisecond timers}

\author{
P. H. Gregson \\ Department of Electrical Engineering, Nova Scotia Technical College, Halifax, Canada
}

W. P. Lonc, S. J.

Physics Department, Saint Mary's University, Hailfax, Canada

We describe two simple and economical timers which are suitable for measuring time intervals with fractional millisecond resolution in physics experiments. For example, in a Fletcher's trolley experiment, a timer could be located at various points along the trolley's path, thus providing values of $\Delta t$ at each of these points. In conjunction with a measurement of a $\Delta x$ at each of these points (e.g., the length of the trolley itself, or the length of a small "flag" riding on the trolley), it is then possible to compute values of the trolley speed at these various points, and eventually to compute the acceleration. Evidently, fairly small values of $\Delta x$ should be chosen. The value of the time interval $\Delta t$ is read directly from the frequency counter. For example, assuming that the 555 integrated circuit (IC) is oscillating at $100 \mathrm{kHz}$, then a display of, say, $2.78 \mathrm{~K}$ counts implies that $\Delta t$ is 27.8 msec. Two versions of a timer are given: one is "light activated" (supplies pulses when the phototransistor is illuminated) and the other is "dark activated" (supplies pulses when the phototransistor is not illuminated). For applications such as the Fletcher's trolley experiment, the "dark-activated" version would be the more appropriate in conjunction with an electronic counter, whereas the "light-activated" unit would be appropriate for measuring camera shutter speeds.

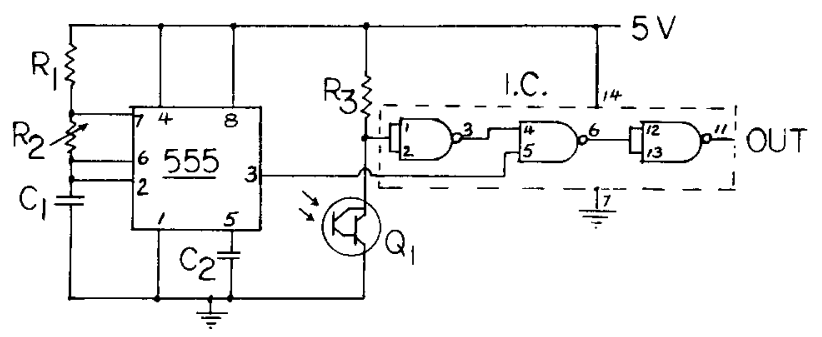

Fig. 1. Schematic of the "light-activated" timer: $100-\mathrm{kHz}$ pulses appear at OUT for the duration of illumination on $Q_{1} . R_{1}=3 \mathrm{k} \Omega, 0.25 \mathrm{~W}$; $R_{2}=10-\mathrm{k} \Omega$ trim pot; $R_{3}=5 \mathrm{k} \Omega, 0.25 \mathrm{~W} ; C_{1}=0.001 \mu \mathrm{F} ; C_{2}=0.01$ $\mu \mathrm{F} ; Q_{1}=$ phototransistor (see text); IC $=$ Fairchild 7400 (or equivalent).

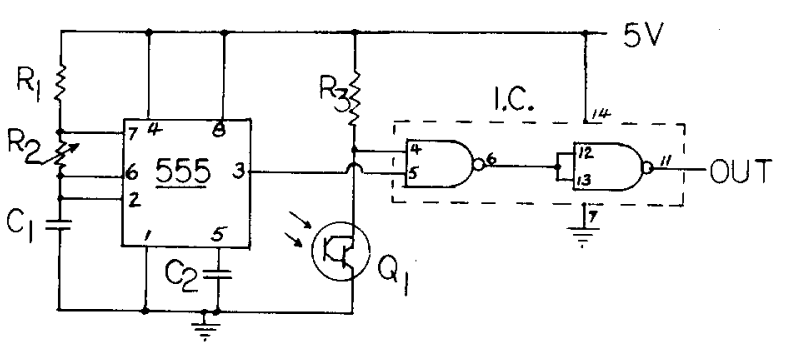

Fig. 2. Schematic of the "dark-activated" timer: $100-\mathrm{kHz}$ pulses appear at out for the duration of no illumination on $Q_{1}$. Parts are the same as for the circuit in Fig. 1.

With reference to the circuit diagrams, the operation of the timer is as follows: The $555 \mathrm{IC}^{\mathbf{1}}$ is adjusted to oscillate at $100 \mathrm{kHz}$ (incidentally, the oscillation frequency is sufficiently independent of power supply variations for the proposed applications) and this pulse train is fed to one input of a TTL NAND gate. The phototransistor ${ }^{2}$ (a photo-Darlington assembly in our circuit) is suitably connected to the other input of the NAND gate so that the output of the gate is controlled by the conduction state of the phototransistor. Hence, to implement the "lightactivated" operation, the suitable connections are as shown in Fig. 1, and to implement the "dark-activated" operation, the suitable connections are as shown in Fig. 2. Experience has shown that this arrangement is much better than one in which the phototransistor gates or controls the 555 IC. The pulse output is then fed to any available electronic digital counter. Finally, the spectral sensitivity of the phototransistor should be taken into account when choosing the associated light source.

${ }^{1}$ Available for approximately $\$ 1$ from Poly Paks, Box 942 , South Lynnfield, MA 01940.

${ }^{2}$ Available from Poly Paks for $\$ 1$ under Catalog No. 92CU1314. Presumably, any photo-Darlington would work in this circuit. 